\title{
Prevalence and Nematode Infection Level on Gastrointestinal Tract at Horse (Equus caballus) in Bangkalan Madura
}

\section{Prevalensi dan Tingkat Infeksi Nematoda pada Saluran Gastrointestinal Kuda (Equus caballus) di Kabupaten Bangkalan Madura}

\author{
${ }^{1)}$ Elok Apriliawati, ${ }^{2)}$ Mufasirin, ${ }^{3)}$ Wurlina, ${ }^{2)}$ Poedji Hastutiek, ${ }^{2)}$ Lucia Tri Suwanti, ${ }^{4}$ Benjamin \\ Christoffel Tehupuring \\ ${ }^{1)}$ Student, Faculty of Veterinary Medicine, Universitas Airlangga \\ ${ }^{2)}$ Department of Veterinary Parasitology, Faculty of Veterinary Medicine, Universitas Airlangga \\ 3) Department of Veterinary Reproduction, Faculty of Veterinary Medicine, Universitas Airlangga \\ 4) Department of Veterinary Anatomy, Faculty of Veterinary Medicine, Universitas Airlangga \\ Received: o6-08-2019, Accepted: 13-08-2019, Published Online: 16-o8-2019
}

\begin{abstract}
The purpose of this study is to determine the prevalence, infection level, sex and age effect on the infection level of GIT Nematode parasite in a horse. The fecal samples analyzed using the methods of native, sedimentation, floatation, and worm eggs count per gram of feces. Sample examination found 54 positive infected gastrointestinal nematode parasite with prevalence rate of $87 \%$ (54 from 62). The prevalence of Trichonema sp., Strongylus sp., and Parascaris equorum are 37.1\%, 16.1\%, and 1.6\%. There were also mixed infestation like Strongylus sp. and Trichonema sp; Strongylus sp. and Parascaris equorum; Trichonema sp. and Parascaris equorum with total prevalence $27.4 \%, 1.6 \%$, and $3.2 \%$. Sex and age of horse had a very significant and significant effect in prevalence and infection level of Nematode parasite.
\end{abstract}

\section{Keywords : prevalence, infection level, Nematode, and gastrointestinal tract}

\section{Pendahuluan}

Di Indonesia, kuda memegang peranan penting untuk manusia, baik untuk diambil tenaga pada kuda delman, kecepatan dalam berlari pada kuda pacu, daging maupun limbah yang dihasilkan (Soedarto, 1991). Menurut data populasi ternak 2016 dari Dinas Peternakan daerah Bangkalan Madura, Kabupaten Bangkalan memiliki populasi kuda sebanyak 601 ekor, kuda dipelihara untuk dimanfaatkan sebagai kuda delman dan kuda pacu.

Kuda pacu di Kabupaten Bangkalan Madura memiliki sanitasi, sistem pemeliharaan dan pakan yang baik, serta diberikan obat cacing secara rutin yang diawasi oleh dokter hewan. Berbeda dengan kondisi kesehatan kuda delman yang terlihat memprihatinkan karena banyak kuda yang kurus, tidak terawat, dan tenaga kuda yang dieksploitasi tanpa ditunjang dengan kebutuhan nutrisi yang cukup dan perawatan yang baik. Salah satu faktor pendukung kondisi tersebut antara lain yaitu adanya infeksi cacing. Penelitian tentang infeksi cacing pada kuda di Kabupaten Bangkalan pernah dilaporkan oleh Hastutiek dkk. (2001) tetapi setelah itu belum pernah dilaporkan kembali.
Masalah utama di sebagian besar negara maju dan negara berkembang adalah infeksi cacing yang menyebabkan penurunan kesehatan dan performa dari kuda. Infeksi cacing ringan sampai sedang tidak selalu menampakkan gejala klinis yang nyata, sedangkan infeksi berat cacing dewasa dapat menyebabkan gangguan pencernaan dan terhambatnya pertumbuhan pada kuda (Subekti dkk., 2010). Infeksi cacing pada kuda dewasa memiliki prevalensi yang lebih rendah, hal tersebut dikarenakan sistem imun pada kuda dewasa sudah berkembang dengan baik dibandingkan kuda yang masih muda (Love, 2003).

Penurunan kesehatan kuda dapat dipengaruhi oleh kondisi lingkungan yang buruk, iklim yang sesuai untuk perkembangbiakan cacing dan pakan yang terkontaminasi larva infektif, terdapat parasit cacing (Soulsby, 1986; Levine, 1990; Koesdarto dkk., 2007). Penurunan kekebalan terhadap parasit pada kuda disebabkan oleh perubahan kadar hormon, stress dan kebuntingan, pada kuda betina memiliki prevalensi infeksi cacing yang tinggi dibanding kuda jantan (Kuchai dkk., 2011).

Penelitian tentang cacing Nematoda gastrointestinal pada kuda dilaporkan oleh 
Ratnawati (2004), jenis cacing Nematoda pada kuda delman di Kota Bogor ditemukan Strongyloid dengan prevalensi $70 \%$, Ascarid 46,6\% dan Oxyurid 30\%. Pradana (2012) melakukan penelitian pada kuda pacu di PT. KTS Pohsarang, Kediri, dengan prevalensi Strongylus sp. $34,78 \%$ dan Trichonema sp. 8,70\%. Siregar (2016) melaporkan bahwa Strongylus sp. 32\%, Trichonema sp. $2 \%$, dan Parascaris equorum $2 \%$ ditemukan pada kuda di Kota Batu, Jawa Timur.

Berdasarkan latar belakang tersebut maka perlu dilakukan penelitian tentang nematoda pada kuda, karena belum ada laporan kembali mengenai prevalensi cacing Nematoda pada saluran gastrointestinal kuda di Kabupaten Bangkalan Madura. Data yang diperoleh, diharapkan dapat digunakan sebagai usaha dalam pencegahan nematodosis pada kuda.

\section{Metode Penelitian}

Penelitian ini menggunakan 62 sampel feses kuda delman dan beberapa spesies kuda pacu yang diambil dari Kecamatan Socah, Burneh, dan Tanah Merah Kabupaten Bangkalan Madura. Bahan yang digunakan dalam penelitian ini adalah feses kuda, formalin $10 \%$, aquadest, dan gula jenuh. Alat yang digunakan adalah: plastik, kertas label, tabung sentrifuse, sentrifuse, coolbox, saringan teh, pengaduk, gelas ukur, gelas plastik, pipet Pasteur, object glass, cover glass, mortar, kamar hitung Mc Master, mikroskop, timbangan analitik, optilab, dan kamera. Sampel diperiksa menggunakan metode natif, sedimentasi, pengapungan dan sampel positif dilanjutkan dengan perhitungan telur cacing per gram tinja kemudian difoto dan diukur menggunakan Optilab.

\section{Analisis Data}

Data yang diperoleh diolah dengan menggunakan rumus prevalensi sebagai berikut (Fuentes dkk., 2004). Prevalensi dihitung berdasarkan sampel + / total sampel dinyatakan dalam \%.

Untuk mengetahui pengaruh perbedaan jenis kelamin dan umur kuda terhadap prevalensi dan tingkat infeksi dianalisis menggunakan Chi Square Test. Seluruh proses analisis menggunakan sistem SPSS Statistic 23 for windows.

\section{Hasil dan Pembahasan}

Berdasarkan hasil penelitian yang sudah dilakukan pada 62 feses kuda yang diambil dari Kabupaten Bangkalan Madura, diketahui terdapat 54 sampel positif terinfeksi cacing Nematoda pada saluran gastrointestinal dengan prevalensi sebesar $87 \%$. Jenis telur cacing yang ditemukan pada saluran gastrointestinal kuda delman dan kuda pacu adalah Strongylus sp., Trichonema sp., dan Parascaris equorum. Prevalensi cacing Nematoda kuda delman dan kuda pacu dapat dilihat pada Tabel 1.

Tabel 1. Prevalensi Cacing Nematoda Saluran Gastrointestinal Kuda di Kabupaten Bangkalan Madura

\begin{tabular}{|c|c|c|c|}
\hline $\begin{array}{l}\text { Jenis Cacing } \\
\text { Nematoda }\end{array}$ & $\begin{array}{c}\text { Kuda } \\
\text { Delman } \\
(\%)\end{array}$ & $\begin{array}{c}\text { Kuda } \\
\text { Pacu } \\
(\%)\end{array}$ & $\begin{array}{c}\text { Jumlah } \\
\text { Persentase } \\
(\%)\end{array}$ \\
\hline Strongylus sp. & 8,1 & 8,1 & 16,1 \\
\hline Trichonema sp. & 22,6 & 14,5 & 37,1 \\
\hline $\begin{array}{l}\text { Parascaris } \\
\text { equorum }\end{array}$ & 1,6 & - & 1,6 \\
\hline $\begin{array}{l}\text { Strongylus sp. } \\
\text { Trichonema sp. }\end{array}$ & 19,4 & 8,1 & 27,4 \\
\hline $\begin{array}{l}\text { Strongylus sp. } \\
\text { Parascaris }\end{array}$ & 1,6 & - & 1,6 \\
\hline $\begin{array}{l}\text { equorum } \\
\text { Trichonema sp. } \\
\text { Parascaris }\end{array}$ & 1,6 & 1,6 & 3,2 \\
\hline equorum & & & \\
\hline Total & & & 87 \\
\hline
\end{tabular}

Berdasarkan pemeriksaan feses kuda delman dan kuda pacu persentase terbesar adalah infeksi tunggal dari Trichonema sp. dengan prevalensi sebesar 37,1\%. Telur cacing Trichonema sp. ditemukan baik dengan metode natif, sedimentasi dan pengapungan. Pada metode apung lebih banyak telur cacing Trichonema sp., hal tersebut dikarenakan pada metode apung berat jenis cacing Trichonema sp. lebih ringan dari berat jenis gula jenuh. Telur berbentuk oval dengan ukuran 96,88 $\mu \mathrm{m}$ x 51,78 $\mu \mathrm{m}$, mengandung morula kecil dan blastomer besar, dinding sel berlapis, cangkang tipis dan permukaan tidak rata. Telur cacing Trichonema sp. dapat dilihat pada Gambar 1.

Telur cacing Strongylus sp. ditemukan pada 5 sampel kuda delman dan 5 sampel kuda pacu. Infeksi campuran telur cacing Strongylus sp. lebih dominan dengan cacing Trichonema sp. $(27,4 \%)$. Telur cacing Strongylus sp. ditemukan dengan metode natif, sedimentasi dan pengapungan. Telur cacing berbentuk oval, terdapat morula, berdinding tipis, barrel-shaped pada dindingnya dan berukuran $82,31 \mu \mathrm{m} \times 51,00$ $\mu \mathrm{m}$. Telur cacing Strongylus sp. dapat dilihat pada Gambar 1.

Telur cacing Parascaris equorum ditemukan pada 1 sampel infeksi tunggal dan 3 sampel 
infeksi campuran. Telur cacing Parascaris equorum ditemukan dengan metode natif, sedimentasi dan pengapungan. Telur cacing hampir bulat dengan ukuran $84,88 \mu \mathrm{m} \times 77,18$ $\mu \mathrm{m}$, terdapat lapisan albumin, berwarna kuning kecoklatan. Telur cacing Parascaris equorum dapat dilihat pada Gambar 1.
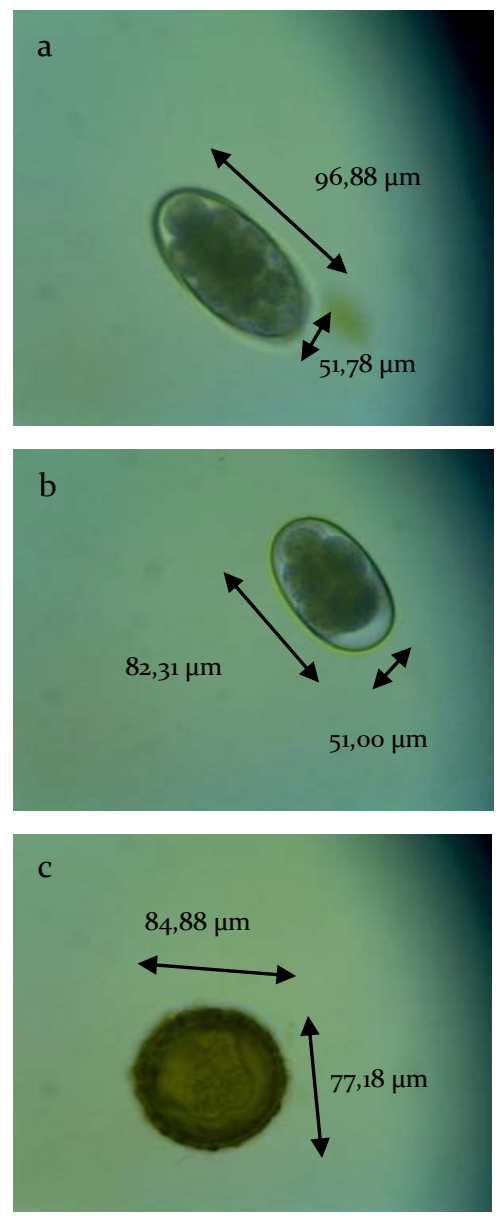

Gambar 1. Telur cacing a) Trichonema sp. b) Strongylus sp. c) Parascaris equorum (perbesaran 400x).
Jumlah telur cacing per gram tinja (TCPGT) berbeda pada setiap sampel. Terdapat 54 sampel positif terinfeksi cacing Nematoda tergolong menjadi dua tingkat infeksi, infeksi ringan 45 sampel dengan rata-rata tingkat infeksi per gram tinja 241,5 dan infeksi sedang 9 sampel dengan rata-rata tingkat infeksi per gram tinja 620. Hasil rata-rata TCPGT cacing Nematoda dapat dilihat pada Tabel 2.

Tabel 2. Rata-rata Telur Cacing Per Gram Tinja Cacing Nematoda pada Saluran Gastrointestinal Kuda

\begin{tabular}{cccc}
\hline $\begin{array}{c}\text { Jumlah } \\
\text { Sampel } \\
\text { Positif }\end{array}$ & $\begin{array}{c}\text { Kategori } \\
\text { Infeksi }\end{array}$ & TCPGT & $\begin{array}{c}\text { Hasil } \\
\text { rata-rata } \\
\text { TCPGT }\end{array}$ \\
\hline 45 & $\begin{array}{c}\text { Infeksi } \\
\text { ringan }\end{array}$ & 0-500 & 241,5 \\
9 & $\begin{array}{c}\text { Infeksi } \\
\text { sedang }\end{array}$ & 501-1000 & 620 \\
\hline
\end{tabular}

Prevalensi cacing Nematoda pada saluran gastrointestinal kuda delman dan kuda pacu menghasilkan nilai signifikan yaitu 0,036 ( $p>0,01$ ), sehingga terdapat pengaruh jenis kuda terhadap prevalensi. Rata-rata telur cacing per gram tinja menghasilkan nilai tidak signifikan yaitu $0,065(p>0,05)$. Prevalensi dan rata-rata telur cacing per gram tinja dapat dilihat pada Tabel 3.

Berdasarkan analisis Chi Square Test menunjukan hasil prevalensi (o,ooz) dan tingkat infeksi $(\mathrm{o}, \mathrm{ooo})$ sangat signifikan $(\mathrm{p}<\mathrm{o}, \mathrm{ol})$ pada faktor jenis kelamin, sehingga. Prevalensi kuda betina (100\%) lebih besar dari kuda jantan $(74,1 \%)$. Rata-rata telur cacing per gram tinja kuda betina $(425,44)$ lebih besar dari kuda jantan $(195,65)$. Prevalensi dan tingkat infeksi cacing Nematoda berdasarkan pengaruh jenis kelamin dapat dilihat pada Tabel 4 .

Tabel 3. Prevalensi dan Rata-rata Telur Cacing Per Gram Tinja pada Kuda Delman dan Kuda Pacu

\begin{tabular}{ccccccc}
\hline Jenis Kuda & $\begin{array}{c}\text { Jumlah } \\
\text { Sampel }\end{array}$ & $\begin{array}{c}\text { Sampel } \\
\text { Positif }\end{array}$ & Persentase (\%) & $\begin{array}{c}\text { Nilai p } \\
\text { prevalensi }\end{array}$ & $\begin{array}{c}\text { Rata-rata } \\
\text { TCPGT }\end{array}$ & $\begin{array}{c}\text { Nilai p } \\
\text { TCPGT }\end{array}$ \\
\hline Delman & 42 & 34 & 80,9 & \multirow{2}{*}{0,036} & 308,82 & \multirow{2}{*}{0,065} \\
Pacu & 20 & 20 & 100 & & & \\
\hline Total & 62 & 54 & & & &
\end{tabular}

Tabel 4. Prevalensi dan Tingkat Infeksi Cacing Nematoda Kuda Berdasarkan Jenis Kelamin

\begin{tabular}{ccccccc}
\hline $\begin{array}{c}\text { Jenis } \\
\text { Kelamin }\end{array}$ & $\begin{array}{c}\text { Jumlah } \\
\text { Sampel }\end{array}$ & $\begin{array}{c}\text { Sampel } \\
\text { Positif }\end{array}$ & Persentase $(\%)$ & $\begin{array}{c}\text { Nilai p } \\
\text { prevalensi }\end{array}$ & $\begin{array}{c}\text { Rata-rata } \\
\text { TCPGT }\end{array}$ & $\begin{array}{c}\text { Nilai p } \\
\text { TCPGT }\end{array}$ \\
\hline Betina & 31 & 31 & 100 & \multirow{2}{*}{,o02 } & 425,44 & \multirow{2}{*}{ o,ooo } \\
Jantan & 31 & 23 & 74,1 & & & \\
\hline Total & 62 & 54 & & & &
\end{tabular}


Tingkat infeksi per gram tinja kuda delman betina $(216,17)$ lebih besar dari kuda pacu betina $(164,8)$. Prevalensi kuda delman jantan $(72 \%)$ lebih rendah dari kuda pacu (100\%). Rata-rata telur cacing per gram tinja kuda delman jantan $(92,5)$ lebih rendah dari kuda pacu jantan $(112,5)$.

Berdasarkan analisis Chi Square Test sampel kuda delman betina dan kuda pacu betina menunjukkan nilai tidak signifikan, semua positif terdapat cacing Nematoda, sehingga tidak terdapat pengaruh antara kuda delman dan kuda pacu betina terhadap prevalensi $(0,590)$ dan tingkat infeksi $(0,106)$ cacing Nematoda. Kuda delman jantan dan kuda pacu jantan memiliki nilai prevalensi $(0,022)$ yang signifikan dan tingkat infeksi (o,ooo) sangat signifikan, sehingga terdapat pengaruh antara kuda delman dan kuda pacu jantan terhadap prevalensi dan tingkat infeksi cacing Nematoda. Prevalensi dan tingkat infeksi cacing Nematoda pada kuda delman dan kuda pacu berdasarkan pengaruh jenis kelamin dapat dilihat pada Tabel 5 .

Berdasarkan analisis Chi Square Test menunjukkan nilai signifikan, sehingga terdapat pengaruh umur kuda terhadap prevalensi $(0,016)$ dan tingkat infeksi (o,o18) cacing Nematoda.
Prevalensi kuda dewasa (78,9\%) lebih rendah dari kuda muda (100\%). Rata-rata telur cacing per gram tinja kuda muda sebesar 385,22 dan lebih besar dari kuda dewasa (257). Prevalensi dan tingkat infeksi telur cacing Nematoda dapat dilihat pada Tabel 6 .

Prevalensi kuda delman dewasa (76,6\%) lebih tinggi dari kuda pacu dewasa (100\%). Ratarata telur cacing per gram tinja pada kuda delman muda $(216,17)$ lebih tinggi dari kuda pacu muda $(164,28)$, sedangkan rata-rata telur cacing per gram tinja kuda delman dewasa $(92,5)$ lebih rendah dari kuda pacu dewasa $(112,5)$.

Berdasarkan analisis Chi Square Test kuda delman dan kuda pacu muda menunjukkan hasil tidak signifikan terhadap prevalensi $(0,693)$ dan tingkat infeksi $(0,896)$ cacing Nematoda. Kuda delman dan kuda pacu dewasa menunjukkan nilai signifikan terhadap prevalensi (o,028) cacing Nematoda, sedangkan tingkat infeksi cacing Nematoda menunjukkan nilai tidak signifikan yaitu 0,105. Prevalensi dan tingkat infeksi cacing Nematoda pada kuda delman dan kuda pacu berdasarkan pengaruh umur dapat dilihat pada Tabel 7 .

Tabel 5. Prevalensi dan Tingkat Infeksi Cacing Nematoda Kuda Delman dan Kuda Pacu Berdasarkan Jenis Kelamin

\begin{tabular}{|c|c|c|c|c|c|c|c|}
\hline $\begin{array}{c}\text { Jenis } \\
\text { Kelamin }\end{array}$ & $\begin{array}{l}\text { Jenis } \\
\text { Kuda }\end{array}$ & $\begin{array}{l}\text { Jumlah } \\
\text { Sampel }\end{array}$ & $\begin{array}{l}\text { Sampel } \\
\text { Positif }\end{array}$ & $\begin{array}{c}\text { Persentase } \\
(\%)\end{array}$ & $\begin{array}{c}\text { Nilai } \mathrm{p} \\
\text { prevalensi }\end{array}$ & $\begin{array}{c}\text { Rata-rata } \\
\text { TCPGT }\end{array}$ & $\begin{array}{l}\text { Nilai p } \\
\text { TCPGT }\end{array}$ \\
\hline \multirow[t]{2}{*}{ Betina } & Delman & 17 & 17 & 100 & \multirow{2}{*}{0,590} & 216,17 & \multirow{2}{*}{0,106} \\
\hline & Pacu & 14 & 14 & 100 & & 164,28 & \\
\hline \multirow[t]{2}{*}{ Jantan } & Delman & 25 & 17 & 68 & \multirow{2}{*}{0,022} & 92,5 & \multirow{2}{*}{0,000} \\
\hline & Pacu & 6 & 6 & 100 & & 112,5 & \\
\hline
\end{tabular}

Tabel 6. Prevalensi dan Tingkat Infeksi Telur Cacing Nematoda Kuda Berdasarkan Umur

\begin{tabular}{ccccccc}
\hline Umur Kuda & $\begin{array}{c}\text { Jumlah } \\
\text { Sampel }\end{array}$ & $\begin{array}{c}\text { Sampel } \\
\text { Positif }\end{array}$ & $\begin{array}{c}\text { Persentase } \\
(\%)\end{array}$ & $\begin{array}{c}\text { Nilai p } \\
\text { prevalensi }\end{array}$ & $\begin{array}{c}\text { Rata-rata } \\
\text { TCPGT }\end{array}$ & $\begin{array}{c}\text { Nilai p } \\
\text { TCPGT }\end{array}$ \\
\hline$<8$ tahun & 24 & 24 & 100 & 0,016 & 385,22 & 0,018 \\
$\geq 8$ tahun & 38 & 30 & 78,9 & 057 & 257 \\
\hline Total & 62 & 54 & & & &
\end{tabular}

Tabel 7. Prevalensi dan Tingkat Infeksi Cacing Nematoda Kuda Delman dan Kuda Pacu Berdasarkan Umur

\begin{tabular}{|c|c|c|c|c|c|c|c|}
\hline $\begin{array}{l}\text { Umur } \\
\text { Kuda }\end{array}$ & $\begin{array}{l}\text { Jenis } \\
\text { Kuda }\end{array}$ & $\begin{array}{l}\text { Jumlah } \\
\text { Sampel }\end{array}$ & $\begin{array}{r}\text { Sampel } \\
\text { Positif }\end{array}$ & $\begin{array}{c}\text { Persentase } \\
(\%)\end{array}$ & $\begin{array}{c}\text { Nilai } \mathrm{p} \\
\text { prevalensi }\end{array}$ & $\begin{array}{c}\text { Rata-rata } \\
\text { TCPGT }\end{array}$ & $\begin{array}{l}\text { Nilai p } \\
\text { TCPGT }\end{array}$ \\
\hline \multirow[t]{2}{*}{$<8$ tahun } & Delman & 13 & 13 & 100 & \multirow{2}{*}{0,693} & 216,17 & \multirow{2}{*}{ o,896 } \\
\hline & Pacu & 11 & 11 & 100 & & 164,28 & \\
\hline \multirow[t]{2}{*}{$\geq 8$ tahun } & Delman & 29 & 21 & 72,4 & \multirow{2}{*}{0,028} & 92,5 & \multirow{2}{*}{0,105} \\
\hline & Pacu & 9 & 9 & 100 & & 112,5 & \\
\hline
\end{tabular}


Prevalensi cacing Nematoda pada kuda di Kabupaten Bangkalan Madura sebesar 87\%. Hasil tersebut lebih besar dari penelitian Siregar (2016) pada kuda di Kota Batu dengan prevalensi $54 \%$. Hal tersebut kemungkinan karena keadaan kuda delman di Kabupaten Bangkalan Madura kurang mendapat nutrisi yang cukup, pakan dan air minum terkontaminasi larva infektif, pembuangan feses tidak jauh dari kandang, dan kurangnya pengetahuan dari peternak. Menurut Subronto (2007) sanitasi, sistem pemeliharaan, kualitas pakan, dan pengobatan mempengaruhi infeksi cacing Nematoda.

Kuda delman di Kabupaten Bangkalan Madura tidak dilengkapi dengan penampung feses sehingga kuda defekasi sembarangan di pinggir jalan dan kebanyakan kuda waktu sore hari sering dilepaskan di lapangan rumput. Kuda pacu terinfeksi cacing Nematoda mungkin karena kuda sudah terinfeksi cacing saat perpindahan kandang, saat kuda diajak jalan-jalan kemungkinan melewati jalan yang biasa dilewati oleh kuda delman, dan waktu sore hari dilepaskan di lapangan rumput di belakang kandang. Kuda delman dan kuda pacu memungkinkan menelan telur infektif yang ada pada rumput dan menyebabkan kuda mengalami infeksi saluran gastrointestinal. Sesuai dengan pernyataan Levine (1990) pada spesies Strongylus sp. larva rabditiform hidup dari mikroorganisme di dalam feses dan pada stadium ketiga larva berselubung lalu meninggalkan feses dan berada di rumput, sehingga larva infektif bisa menginfeksi kuda yang memakan rumput.

Hasil identifikasi pada kuda delman dan kuda pacu ditemukan beberapa spesies cacing Nematoda yaitu Strongylus sp., Trichonema sp., dan Parascaris equorum. Melalui metode natif, sedimentasi, dan pengapungan. Hasil ini berbeda dari penelitian Chemeda dkk. (2016) di Kota Ambo, Ethiopia Tengah menunjukkan jenis cacing Nematoda yang menginfeksi kuda antara lain Thiodontophorus, Strongyles, Oxyuris equi, dan Parascaris equorum. Faktor intrinsik dari tubuh hewan mempengaruhi kepekaan hewan terhadap tingkat infeksi, antara lain spesies hewan, jenis kelamin, umur, dan imunitas hewan (Koesdarto dkk., 2007; Levine, 1990). Perbedaan cacing Nematoda yang ditemukan pada kuda di Kabupaten Bangkalan Madura dengan kuda di Kota Ambo Ethiopia mungkin bisa disebabkan karena tingkat kekebalan dari kuda terhadap penyakit cacingan.

Secara umum infeksi cacing Trichonema sp. terjadi infeksi campuran dengan cacing Strongylus sp. mungkin karena kedua cacing ini memiliki siklus hidup yang sama yaitu secara langsung. Telur dikeluarkan bersama feses, dengan kondisi lingkungan yang sesuai untuk perkembangbiakan cacing lalu telur segera menetas menjadi larva infektif dalam waktu 7 hari, larva infektif tertelan oleh kuda saat memakan rumput yang terinfeksi larva kemudian menyebabkan kegagalan partumbuhan (Subronto, 2007).

Cacing Parascaris equorum positif pada kuda berusia kurang dari 2 tahun. Hal tersebut kemungkinan karena cacing Parascaris equorum hanya menginfeksi kuda dibawah umur 2 tahun. Menurut Rosdalle dan Ricketts (1974) cacing Parascaris equorum lebih banyak menyerang anak kuda, habitatnya berada di usus halus kuda berumur kurang dari 3 tahun dan tidak menyerang kuda tua, selain itu cacing Parascaris equorum dewasa berkembang pada kuda berusia kurang dari 3 tahun, sedangkan pada kuda berumur lebih dari 3 tahun, cacing Parascaris equorum siklus hidupnya tidak berkembang menjadi cacing dewasa.

Semua sampel kuda pacu terinfeksi cacing Nematoda kemungkinan karena lingkungan kuda dan tempat pelepasan kuda sudah terkontaminasi oleh cacing Nematoda sehingga kuda bisa terinfeksi melalui rumput dan air minum. Menurut Soulsby (1982) siklus hidup cacing Nematoda tidak memerlukan inang perantara, sehingga telur cacing bisa menetas pada lingkungan yang sesuai dengan siklus hidup cacing sehingga kuda bisa terinfeksi larva infektif yang tertelan melalui pakan dan air yang terkontaminasi. Sedangkan pada kuda delman terdapat 8 sampel negatif cacing Nematoda kemungkinan karena sampel kuda yang negatif berusia 10 tahun keatas. Semakin dewasa usia kuda tingkat infeksi yang dihasilkan lebih rendah, karena sistim imun dari kuda sudah terbentuk dengan baik dan untuk membentuk sistem imun yang baik diperlukan waktu yang cukup lama (Love, 2003).

Hasil prevalensi dan tingkat infeksi sangat signifikan $(\mathrm{p}<\mathrm{0}, \mathrm{ol})$ pada faktor jenis kelamin, sehingga mempengaruhi prevalensi dan tingkat infeksi cacing Nematoda pada kuda. Prevalensi dan rata-rata telur cacing per gram tinja lebih besar kuda betina dari kuda jantan. Hal tersebut bisa disebabkan karena beberapa sampel yang diambil berasal dari kuda betina yang bunting dan menyusui. Pernyataan tersebut didukung oleh pernyataan Hariadi dkk. (2011) dan Kuchai dkk. (2011) bahwa penurunan kekebalan terhadap parasit pada kuda juga bisa disebabkan oleh penurunan kadar hormon estrogen yang 
menyebabkan kuda menjadi stress, hormon LTH (Luteotrophic Hormone) yang menurunkan sintesis susu dan faktor kebuntingan sehingga pada kuda betina memiliki prevalensi infeksi cacing yang lebih tinggi dari kuda jantan.

Hasil prevalensi dan tingkat infeksi signifikan ( $\mathrm{p}>\mathrm{o}, \mathrm{ol}$ ) pada faktor umur, sehingga terdapat pengaruh umur dari kuda terhadap prevalensi dan tingkat infeksi cacing Nematoda. Prevalensi kuda dewasa lebih rendah dari kuda muda. Rata-rata telur cacing per gram tinja kuda muda lebih besar dari kuda dewasa. Hasil ini sesuai dengan pendapat Levine (1990) bahwa infeksi pada kuda dewasa lebih rendah dari kuda muda, dikarenakan sistim kekebalan tubuh pada kuda dewasa sudah berkembang dengan baik.

Hasil dari perhitungan TCPGT pada kuda di Kabupaten Bangkalan Madura menunjukkan infeksi cacing Nematoda pada saluran gastrointestinal kuda tergolong infeksi ringan dan infeksi sedang. Kuda yang terinfeksi ringan dan terinfeksi sedang tidak menunjukkan gelala klinis seperti lemas, bulu kusam, kekurusan, depresi, kolik, dan diare sehingga kuda harus diberi antihelmintik secara rutin pada kuda dewasa setiap 6 bulan sekali dan pada anak kuda pada umur 6 bulan, setelah itu setiap 2 bulan sesudahnya selama satu tahun (Subronto, 2007).

\section{Kesimpulan}

Jenis cacing Nematoda yang ditemukan di saluran gastrointestinal kuda delman dan kuda pacu adalah Trichonema sp., Strongylus sp., dan Parascaris equorum. Prevalensi cacing Nematoda saluran gastrointestinal kuda di Kabupaten Bangkalan Madura sebesar $87 \%$. Nematodosis saluran gastrointestinal kuda di Kabupaten Bangkalan Madura dipengaruhi oleh faktor jenis kelamin dan umur.

\section{Daftar Pustaka}

Fuentes, S.V,. M. Saez, M. Trelis., C. Munos-atoli, dan G.J. Esteban. 2004. The Helmint Community of Apodemus Sylvaticus (Rodentia, Muridae) in The Sierra de Gredos (Spain). Arxius de Miscellania Zoologica 2:1-6

Hariadi, M., S. Hardjopranyoto, Wurlina, H. A. Hermadi, B. Utomo, Rimayanti, I. N. Triana, dan H. Ratnani. 2011. Buku Ajar Ilmu Kemajiran pada Ternak. Airlangga University Press. Surabaya. Hal:52-55

Hastutiek, P., R. Sasmita dan G. Mahasri. 2001. Prevalensi Infeksi Cacing Saluran
Pencernaan pada Sapi, Kerbau dan Kuda di Kabupaten Bangkalan Madura. Media Kedokteran Hewan 17(1): 67-72

Koesdarto, S., S. Subekti., S.M. Sosiawati., H. Puspitawati dan Kusnoto. 2007. Buku Ajar Ilmu Penyakit Nematoda Veteriner. Departemen Pendidikan Nasional Fakultas Kedokteran Hewan Universitas Airlangga. Surabaya. Hal: 1-5

Kuchai, J.A., M.Z. Chishti, M.M. Zaki, J. Ahmad, M. Rasool, S.A. Dar and Tak. 2011. Epidemology Of Helminth Parasites In Small Ruminant Of Ladakh, India. Pnline J. Anim. Feed Res. 1(5) : 239-242

Levine, N.D. 1990. Buku Pelajaran Parasitologi Veteriner. Gadjah Mada University Press. Yogyakarta. Hal: 171-458

Love, S. 2003. Treatment and prevention of intestinal parasite associated disease. Vet. Clin. Equine. 19: 791 - 806

Pradana, F.H.A. 2012. Tingkat Kejadian Helminthiasis Gastrointestinal pada Kuda Pacu di PT. KTS Pohsarang, Kediri. [Skripsi] Fakultas Kedokteran Hewan, Universitas Airlangga. Surabaya.

Ratnawati, E.W. 2004. Kejadian Infeksi Cacing Parasit Saluran Pencernaan pada Kuda Delman di Kota Bogor. [Skripsi] Fakultas Kedokteran Hewan Institut Pertanian Bogor. Bogor.

Siregar, D.O. 2016. Prevalensi Cacing Nematoda dan Derajad Infeksi Nematodiasis Kuda di Kota Batu. [Skripsi] Fakultas Kedokteran Hewan, Universitas Airlangga. Surabaya.

Soedarto. 1991. Helmintologi Kedokteran. Cetakan I EGC. Jakarta.

Soulsby, E.J.L. 1982. Helminths, Arthropods and Protozoa of Domesticated Animals, $7^{\text {th }}$ Ed., Bailliere, Tindal and Cassell Ltd. London.

Soulsby, E.J.L. 1986. Helminths, Arthropods and Protozoa of Domesticated Animals, $7^{\text {th }}$ Ed., Bailliere, Tindal and Cassell Ltd. London.

Subekti, S., S. Mumpuni, S. Soedarto, H. Puspitawati dan Kusnoto. 2010. Buku Ajar Parasitologi Veteriner. Fakultas Kedokteran Hewan Universitas Airlangga. Surabaya.

Subronto. 2007. Ilmu Penyakit Ternak II. Gadjah Mada University Press. Yogyakarta. Hal: 64109 